\title{
Calcium channels are involved in EphB/ephrinB reverse signaling-induced apoptosis in a rat chronic ocular hypertension model
}

\author{
LINGDAN DONG $^{1}$, XIANGLIN CHENG ${ }^{2}$, LONG ZHOU $^{3}$ and YANHONG HU ${ }^{4}$ \\ ${ }^{1}$ Central Laboratory; Departments of ${ }^{2}$ Neurology and ${ }^{3}$ Pathology, First People's Hospital of Jingzhou, First Affiliated Hospital of \\ Yangtze University; ${ }^{4}$ Nursing Department of Medical School of Yangtze University, Jingzhou, Hubei 434000, P.R. China
}

Received August 19, 2017; Accepted November 21, 2017

DOI: $10.3892 / \mathrm{mmr} .2017 .8162$

\begin{abstract}
Erythropoietin-producing hepatocyte receptor B (EphB)/ephrinB reverse signaling has been revealed to be activated in chronic ocular hypertension $(\mathrm{COH})$ by increasing the apoptosis of retinal ganglion cells (RGCs). However, the exact mechanism is not well understood. The present study investigated the involvement of $\mathrm{Ca}^{2+}$ channels in the apoptosis of RGCs induced by EphB/ephrinB reverse signaling in a rat $\mathrm{CHO}$ model, which was established by cauterizing 3 out of the 4 episcleral veins. The expression levels of four voltage-gated $\mathrm{Ca}^{2+}$ channel subunits $\left(\mathrm{Ca}_{\mathrm{v}} 3.1-3.3\right.$ and $\left.\mathrm{Ca}_{\mathrm{v}} 1.2\right)$ were detected using immunofluorescence and western blot analysis. TUNEL staining was performed to assess RGC apoptosis following an injection with the $\mathrm{T}$ type $\mathrm{Ca}^{2+}$ channel blocker. $\mathrm{Ca}^{2+}$ channels, mainly the $\mathrm{T}$ type, were upregulated in $\mathrm{COH}$ rat retinas when compared with the sham group $(\mathrm{P}<0.01)$. Additionally, the $\mathrm{Ca}_{\mathrm{v}} 3.2$ subunit of $\mathrm{T}$ type calcium channels was predominantly expressed in Müller cells and RGCs, such as ephrinB2. Furthermore, an intravitreal injection of the $\mathrm{Ca}^{2+}$ channel blocker Mibefradil $(3 \mu \mathrm{M})$ reduced EphB2-fragment crystallizable region-induced RGC apoptosis in normal rats. Thus, the results suggest that $\mathrm{Ca}^{2+}$ channels in a $\mathrm{COH}$ model may be a pathway involved in ephrinB/EphB signaling-induced RGC apoptosis.
\end{abstract}

Correspondence to: Dr Lingdan Dong, Central Laboratory, First People's Hospital of Jingzhou, First Affiliated Hospital of Yangtze University, 8 Hangkong Road, Jingzhou, Hubei 434000, P.R. China E-mail:09110700016@fudan.edu.cn

Ms. Yanhong $\mathrm{Hu}$, Nursing Department of Medical School of Yangtze University, 1 Nanhuan Road, Jingzhou, Hubei 434000, P.R. China

E-mail: 4159808@qq.com

Key words: calcium channel, EphB/ephrinB reverse signaling, glaucoma, retinal ganglion cells, chronic ocular hypertension, apoptosis

\section{Introduction}

One of the largest tyrosine kinase families, erythropoietin-producing hepatocyte receptors (Ephs) and their corresponding ligands, ephrins, are expressed in neighboring cells with reciprocal pattern (1). The interaction between receptors and ligands plays an important role in different kinds of diseases (2-8). Interactions between Eph receptors and NMDA receptors and/or metabotropic glutamate receptors have been reported to cause excitotoxic neuronal death in central nervous system (CNS) (8-13). Eph receptors have also shown to be important in both experimental glaucomatous animals and spontaneous glaucomatous DBA/2J mice $(14,15)$. Our previous study has shown that interaction between ephrinB/EphB signaling and AMPA receptor subunits GluA2 contributes to retinal ganglion cells (RGCs) apoptosis in a rat chronic ocular hypertension $(\mathrm{COH})$ model (16). Since Eph receptor signaling casts a wide net on cellular behavior, there are probably other pathways involved in RGCs injury induced by ephrinB/EphB signaling in $\mathrm{COH}$ model. The study on the optic nerve head $(\mathrm{ONH})$ of the DBA/2J mice showed that EphB2-Fc increased intracellular $\mathrm{Ca}^{2+}$ concentrations in single RGCs axons (14). Although different kinds of $\mathrm{Ca}^{2+}$ permeable receptors which mediated $\mathrm{Ca}^{2+}$ overload have been indicated in the RGCs apoptosis in retina (17-19), elevated levels of $\mathrm{Ca}^{2+}$ concentrations through voltage-gated $\mathrm{Ca}^{2+}$ channels have been associated with diminished vision in healthy aging (20). Also, according to study on glaucoma prevalence, calcium oral intake without calcium channel antagonist can increase the risk for glaucoma $(21,22)$. Based on these evidences, the aim of the present study was to investigate the role of calcium channels in a rat $\mathrm{COH}$ model and whether these channels can be regulated by ephrinB/EphB signaling.

\section{Materials and methods}

Animals and rat $\mathrm{COH}$ model. Male Sprague Dawley rats, that were 3 to 4 weeks of age and weighted 100-250 g, were obtained from Shanghai Laboratory Animal Center Laboratory Animal Co., Ltd. All the animals were housed in an environment with temperature of $22 \pm 1^{\circ} \mathrm{C}$, relative humidity of $50 \pm 1 \%$ and a light/dark cycle of $12 / 12 \mathrm{~h}$. Both food and 
water were provided ad libitum. All experimental procedures described were in accordance with the National Institutes of Health guidelines for the Care and Use of Laboratory Animals and the Guidelines of the Yangtze University on the Ethical Use of Animals. Care and use of animals were also approved by the ethics committee of First Affiliated Hospital of Yangtze University (Jingzhou, China).

$\mathrm{COH}$ rat model was established and validated following the previously described approach $(16,23,24)$. Briefly, rats were anesthetized with a mixture of ketamine $(25 \mathrm{mg} / \mathrm{kg}$, im) and xylazine $(10 \mathrm{mg} / \mathrm{kg}, \mathrm{im})$; eyes were locally anesthetized with topical $0.4 \%$ oxybuprocaine hydrochloride drops (Benoxil; Santen Pharmaceutical, Co., Ltd., Ishikawa, Japan). Three episcleral veins in the left eye were carefully separated and cauterized under an OPMI VISU 140 microscope (Carl Zeiss, Oberkochen, Germany). A sham operation, following a similar procedure (except for not occluding the vines), was conventionally performed on the eyes of other rats. After surgery, eyes were flushed with antibiotic eye drops and covered with antibiotic ointment. Intraocular pressure (IOP) was measured using a handheld digital tonometer (Tonopen XL; Mentor O\&O, Norwell, IL, USA) under general and local anesthesia as described above. The average value of five consecutive acceptable measurements with a deviation $<5 \%$ was recorded. All measurements were performed in the morning to avoid possible circadian differences. IOPs in both eyes were measured before surgery (baseline), immediately after surgery (day 0), the first day after surgery (G1 day), the third day after surgery (G3 days) and weekly thereafter.

Western blotting. Western blot analysis was conducted as previously described $(16,23,24)$, with some modifications. Previous studies have demonstrated that $\mathrm{Ca}_{\mathrm{v}} 3.1, \mathrm{Ca}_{\mathrm{v}} 3.2$ and $\mathrm{Ca}_{\mathrm{v}} 3.3$ subunits of T-type $\mathrm{Ca}^{2+}$ channels and the $\mathrm{Ca}_{\mathrm{v}} 1.2$ subunit of L-type $\mathrm{Ca}^{2+}$ channels are mainly expressed in rat retinal Müller cells and RGCs layer (25). Since both ganglion cell layer and Müller cells are vulnerable to IOP, we examined $\mathrm{Ca}^{2+}$ channels subunits change in $\mathrm{COH}$ retinas using Western blot. Retinas were homogenized in RIPA lysis buffer (cat. no. 89900; Pierce; Thermo Fisher Scientific, Inc., Waltham, MA, USA) supplemented with protease and phosphatase inhibitor cocktail (cat. no. 88661\&88662; Roche Applied Science, Mannheim, Germany). The concentration of total proteins was measured using a standard bicinchoninic acid assay kit (cat. no. 23227, Pierce; Thermo Fisher Scientific, Inc., Waltham, MA, USA). The extracted whole protein samples $(50 \mu \mathrm{g})$ were resolved by $8 \%$ SDS-PAGE gel and electroblotted onto PVDF membranes (cat. no. ISEQ0001, Immobilon-P; EMD Millipore, Billerica, MA, USA) using Mini-PROTEAN 3 Electrophoresis System and Mini Trans-Blot Electrophoretic Transfer System (Bio-Rad Laboratories, Inc., Hercules, CA, USA). After being blocked in $5 \%$ nonfat milk at room temperature for $1.5 \mathrm{~h}$, the membranes were incubated at $4^{\circ} \mathrm{C}$ overnight with the following primary antibodies: monoclonal mouse anti- $\beta$-actin (cat. no. A2228, 1:3,000 dilution; Sigma-Aldrich; Merck KGaA, Darmstadt, Germany), polyclonal rat anti-Ca 3.1 (cat. no. ACC-021), anti-Ca 3.2 (cat. no. ACC-025), anti-Ca 3.3 (cat. no. ACC-009), anti-Ca 1.2 (cat. no. CC-003) (1:200 dilution for all the three; Alomone Labs, Jerusalem, Israel). After being washed in Tris-buffered saline-Tween-20 (TBST) for three times (5-10 min per time), the blots were incubated with horseradish-peroxidase-(HRP-) conjugated donkey anti-mouse (Cat no. 715-035-151) or donkey anti-rabbit (cat. no. 715-035-151) secondary antibody (Jackson ImmunoResearch Laboratories, Inc., West Grove, PA, USA) for $2 \mathrm{~h}$ at room temperature. Blots were then washed in TBST for another three rounds, and incubated with chemofluorescent reagent (cat. no. 34080; Pierce; Thermo Fisher Scientific, Inc.) followed by exposure to X-ray film in a dark room. Experiments were performed in triplicate. The protein bands were quantitatively analyzed with NIH Image Analysis software (Image J, version 1.38x; National Institutes of Health, Bethesda, MD, USA). Protein levels were normalized to the corresponding $\beta$-actin levels.

Immunofluorescence analysis. As previously described $(16,23)$, retinal sections were examined by immunofluorescence technique. Rats were anesthetized with ethyl carbamate $(1.25 \mathrm{~g} / \mathrm{kg}$, ip; Sinopharm Chemical Reagent Co. Ltd., Shanghai, China) and transcardially perfused with $4 \%$ paraformaldehyde (PFA; in 0.1 M PB, pH 7.4). Eyes were post-fixed in 4\% PFA for 2-4 $\mathrm{h}$ and then dehydrated with graded sucrose solutions at $4^{\circ} \mathrm{C}$ ( $4 \mathrm{~h}$ in $20 \%$ and overnight in $30 \%$ solutions). Retinas were vertically sectioned (14 $\mu \mathrm{m}$; Leica Microsystems $\mathrm{GmbH}$, Wetzlar, Germany), and sections were mounted on chrome-alum-gelatin-coated slides (Thermo Fisher Scientific, Inc.). Sections were then blocked for $2 \mathrm{~h}$ in $6 \%$ normal donkey serum, $1 \%$ bovine serum, and $0.2 \%$ Triton $\mathrm{X}-100$, and dissolved in PBS at room temperature. Consequently, sections were incubated with the following primary antibodies at $4^{\circ} \mathrm{C}$ for $24 \mathrm{~h}$ : polyclonal rat anti-Ca 3.1 , anti- $\mathrm{Ca}_{\mathrm{v}} 3.2,(1: 200$ dilution; Alomone Labs, Jerusalem, Israel), Goat anti-CTB (cat. no. 703; List Biological Laboratories, Campbell, CA, USA), mouse anti-glial fibrillary acidic protein (GFAP, cat. no. G3893; Sigma-Aldrich; Merck KGaA). Binding sites of primary antibodies were visualized by incubating sections with: 488-conjugated donkey anti-rabbit secondary antibodies (cat. no. 711-546-152, 1:400; Jackson ImmunoResearch Laboratories, Inc.) for single $\mathrm{Ca}_{\mathrm{v}} 3.2$ vision, and cy3-conjugated donkey anti-rabbit (cat. no. 711-165-152), cyanine conjugated donkey anti-goat (cat. no. 705-175-147), 488-conjugated donkey anti-mouse (cat. no. 715-545-150) were used to stain the co-localization of $\mathrm{Ca}_{\mathrm{v}} 3.2$, CTB and GFAP. All the secondary antibodies were incubated for $2 \mathrm{~h}$ at room temperature. Finally, sections were visualized and photographed with a Leica SP2 confocal laser-scanning microscope. To avoid reconstruction stacking artifacts, double labeling was evaluated by sequential scanning on single-layer optical sections at $1.0 \mu \mathrm{m}$ intervals.

$C T B$ injection for retrograde labeling of RGCs. Retrograde labeling of RGCs was previously described in detail (23). Briefly, after anesthetizing rats with $40 \mathrm{mg} / \mathrm{ml}$ sodium pentobarbital $(0.1 \mathrm{ml} / 100 \mathrm{~g}), 1 \%$ Cholera Toxin B subunit (CTB, cat. no. 104; List Biological Laboratories) was injected into the superior colliculus $(6.0 \mathrm{~mm}$ posterior and $2.0 \mathrm{~mm}$ lateral to the bregma, and 4-5 mm deep from the cortical surface). After a survival period of 5-7 days, RGCs were clearly labeled for immunofluorescence analysis.

Clustering of EphB2-Fc. The EphB2-Fc (cat. no. 467-B2-200, $2 \mu \mathrm{g} / \mu \mathrm{l}$; R\&D Systems, Inc., Minneapolis, MN, USA) was 
clustered by a $40 \mathrm{~min}$ incubation at $37^{\circ} \mathrm{C}$ in buffer containing an AffiniPure goat anti-human IgG, Fc-specific (1:2.5 w/w) (Jackson ImmunoResearch, Milan, Italy) (26).

Intravitreal injection. Intravitreal injection was performed according to previously described method $(16,24)$. When the pupil of the anesthetized eye was dilated with tropicamide drops, clustered EphB2-Fc (2 $\mu 1$, ), or Mibefradil (no. M5441, $3 \mathrm{mM}$; Sigma-Aldrich; Merck KGaA) dispersed in $2 \mu \mathrm{l}$ of $0.9 \%$ saline, was injected into the vitreous space through a postlimbus spot using stereoscopic microscope (Carl Zeiss). A 30 -gauge needle was then inserted $2 \mathrm{~mm}$ behind the temporal limbus and directed toward the optic nerve. Eyes of vehicle or negative control $(\mathrm{Ctr})$ group were injected with saline or clustered human Ig-Fc (2 $\mu \mathrm{g}$; R\&D Systems, Inc.), respectively.

Cell apoptosis. To investigate cell apoptosis, terminal deoxynucleotidyl transferase-mediated biotinylated UTP nick end labeling (TUNEL) assay $(16,23)$ was performed on whole flat-mounted retinas using the DeadEnd Fluorometric TUNEL System G3250 kit (Promega Corporation, Madison, WI, USA), following the manufacturer's instructions. TUNEL signals were visualized with a laser confocal scanning microscope through a 20x objective (FluoView 1000; Olympus Corporation, Tokyo, Japan). The retinas were mounted with the ganglion cell layer (GCL); a serial deep scanning was performed in the GCL according to the DAPI staining results. All TUNEL-positive signals that merged well with DAPI in each retina in GCL, were consequently counted (comparing with INL and ONL, the cell body in GCL was the largest).

Statistical analysis. The data derived from the TUNEL assay and the IOP monitoring were presented as mean \pm SEM. For Western blot experiments, the expression level of a protein was first normalized to the corresponding $\beta$-actin levels. The relative expression levels were averaged for all samples. The mean values of the data obtained during different postoperational time periods were normalized according to the mean value of the control group. The data were presented as the mean \pm SEM. A one-way ANOVA with LSD post hoc test (for protein analysis and RGCs apoptosis), or $t$ test (paired data for IOP analysis) were used and $\mathrm{P}<0.05$ was considered to indicate a statistically significant difference.

\section{Results}

Expression change of $\mathrm{Ca}^{2+}$ channels in rat $\mathrm{COH}$ model. The rat $\mathrm{COH}$ model, with increased IOP levels, was successfully established and validated according to previously described method (16). Briefly, significantly higher IOP was observed in $\mathrm{COH}$ rats compared to sham and unoperated group $(\mathrm{COH}$ : $25.0 \pm 0.7$ to $28.2 \pm 1.2 \mathrm{mmHg}, \mathrm{n}=10-74$; sham: $19.0 \pm 0.6$ to $19.7 \pm 0.9 \mathrm{mmHg}, \mathrm{n}=10-74$; unoperated eyes: $19.8 \pm 1.0 \mathrm{mmHg}$, $\mathrm{n}=9$, all $\mathrm{P}<0.001$ ).

As the summary data showed, the average intensity of $\mathrm{Ca}_{\mathrm{v}} 3.1$ increased from G1 day until G3 weeks while that of $\mathrm{Ca}_{\mathrm{v}} 3.2$ increased later from $\mathrm{G} 1$ week until G4 weeks (Fig. 1B and C). The protein level of $\mathrm{Ca}_{\mathrm{v}} 3.1$ on G1 day was increased to $123.9 \pm 3.6 \%$ of control $(\mathrm{n}=4, \mathrm{P}=0.006$ and further increased to $208.0 \pm 4.3,241.3 \pm 9.5,224.4 \pm 10.6$ and
A

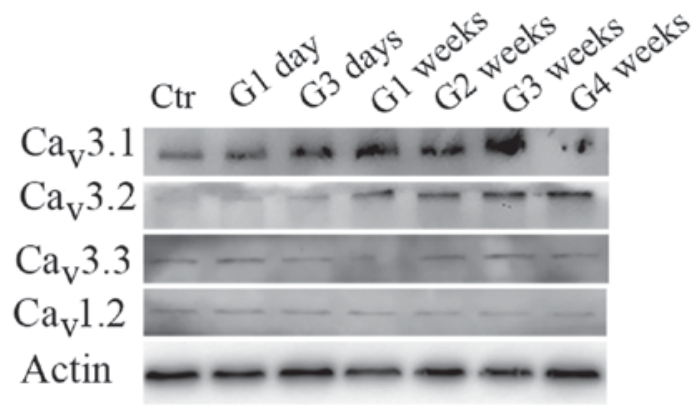

B $\mathrm{Ca}_{\mathrm{v}} 3.1$

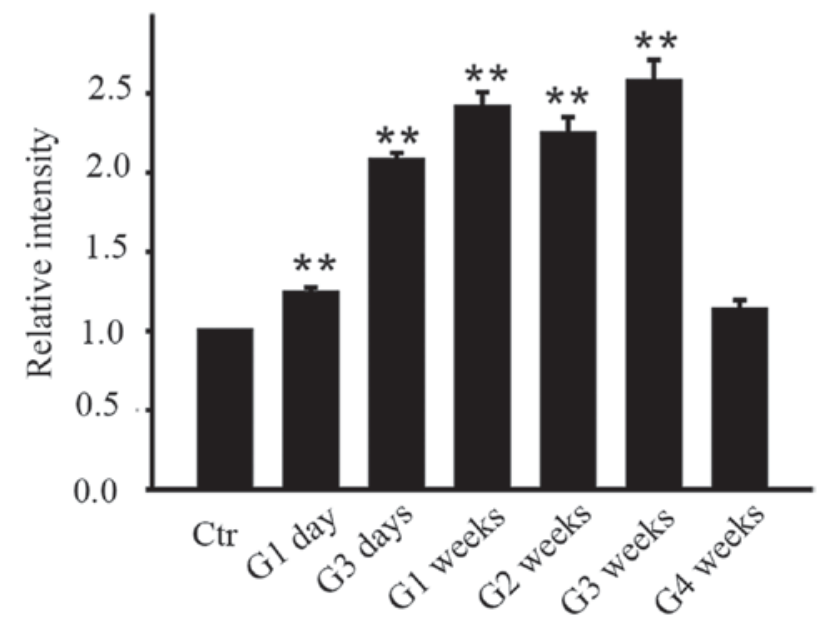

C $\mathrm{Ca}_{\mathrm{v}} 3.2$

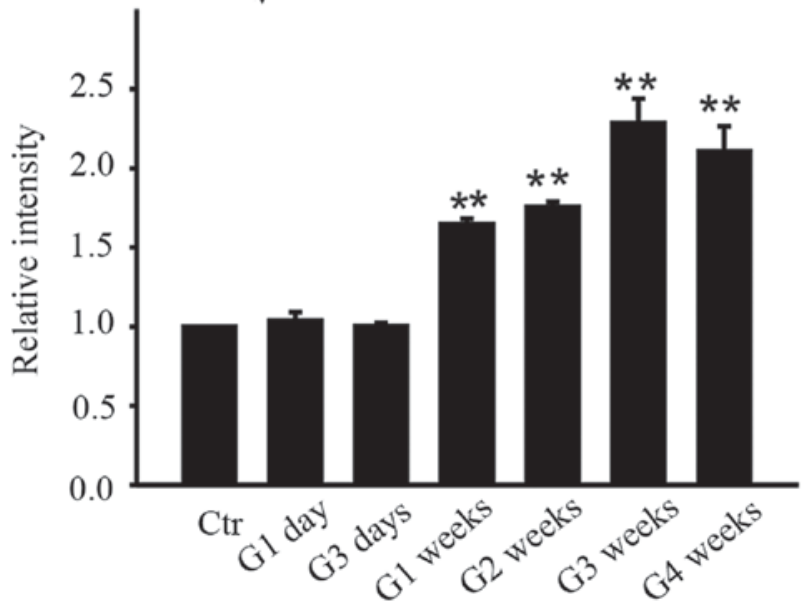

Figure 1. Differences in the protein levels of $\mathrm{Ca}_{\mathrm{v}} 3.1, \mathrm{Ca}_{\mathrm{v}} 3.2, \mathrm{Ca}_{\mathrm{v}} 3.3$ and $\mathrm{Ca}_{\mathrm{v}} 1.2$ in the retinas of sham and $\mathrm{COH}$ rats. (A) $\mathrm{Ca}_{\mathrm{v}} 3.1, \mathrm{Ca}_{\mathrm{v}} 3.2, \mathrm{Ca}_{\mathrm{v}} 3.3$ and $\mathrm{Ca}_{\mathrm{v}} 1.2$ expression in sham-operated and $\mathrm{COH}$ retinal extracts at different time points (G1 day, G3 days, G1 week, G2 weeks, G3 weeks and G4 weeks). Bar charts summarizing the average densitometric quantification of immunoreactive bands of (B) $\mathrm{Ca}_{\mathrm{v}} 3.1$ and (C) $\mathrm{Ca}_{\mathrm{v}} 3.2$ expression during different time points. All data were normalized to control and are presented as the mean \pm standard error of the mean. ${ }^{* *} \mathrm{P}<0.01$ vs. Ctr. Ctr, sham-operated control; G1 day, 1 day following surgery; G3 days, 3 days following surgery; G1-4 weeks, 1-4 weeks following surgery; $\mathrm{Ca}_{\mathrm{v}}$, calcium channel; $\mathrm{COH}$, chronic ocular hypertension.

$257.7 \pm 13.5 \%$ of control at G3 days, G1 week, G2 weeks and G3 weeks respectively (all $\mathrm{n}=4, \mathrm{P}<0.001$ ) and then unexpectedly returned to the control level at G4 weeks $(113.1 \pm 6.3 \%$ of control, $\mathrm{n}=4, \mathrm{P}=0.109$ ) (Fig. 1B). As for $\mathrm{Ca}_{\mathrm{v}} 3.2$, the protein 


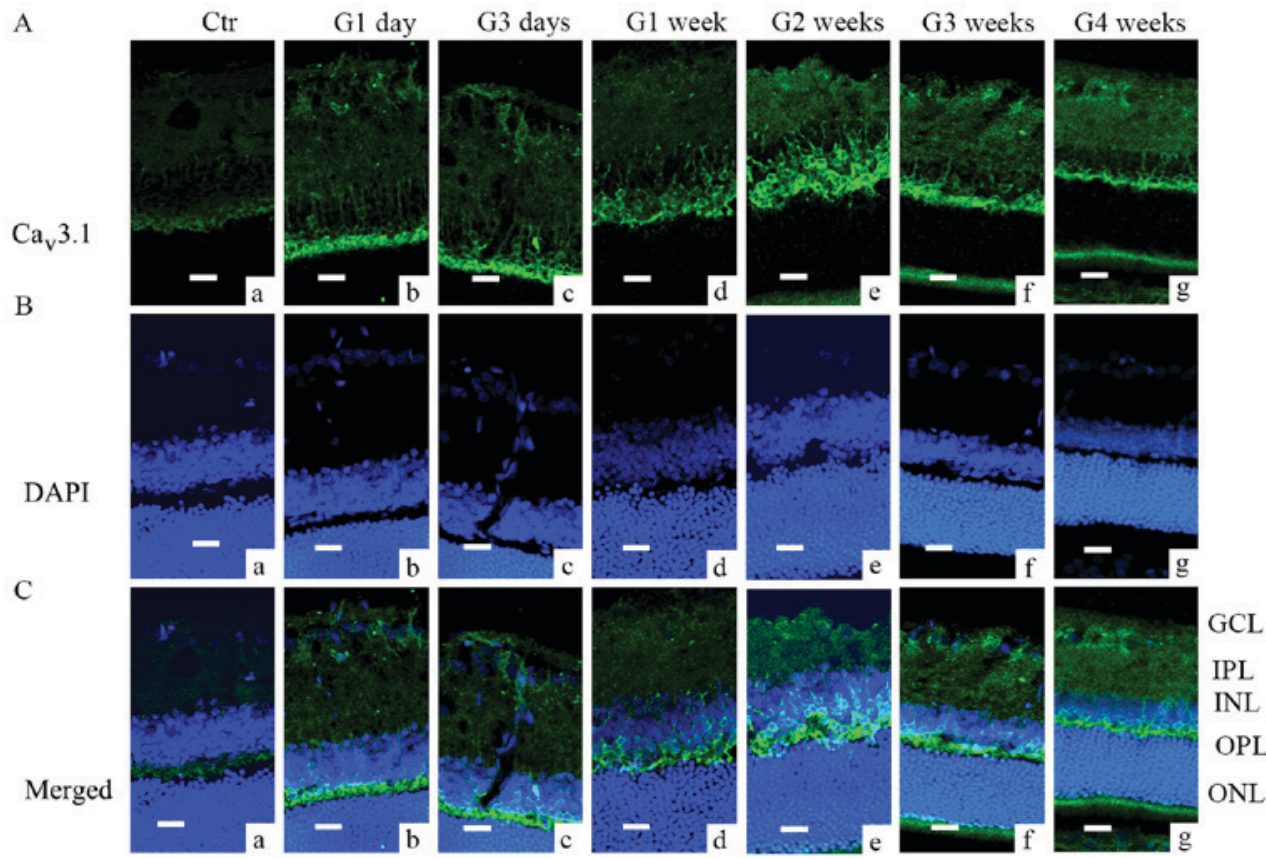

Figure 2. $\mathrm{Ca}_{\mathrm{v}} 3.1$ expression in $\mathrm{COH}$ rats examined by immunofluorescence. (A) $\mathrm{Ca}_{\mathrm{v}} 3.1$ expression profiles in rat retinal vertical slices taken from sham-operated retinas (Ctr; image a), and those obtained from $\mathrm{COH}$ rats at different time points (images b-g). (B) DAPI staining in retinas of control rats (image a), and those obtained from $\mathrm{COH}$ rats at different time points (images b-g). (C) Merged images of $\mathrm{Ca}_{\mathrm{v}} 3.1$ and DAPI in retinas of control rats (a), and those obtained from $\mathrm{COH}$ rats at different time points (images a-g). Scale bars=20 $\mu \mathrm{m}$. GCL, ganglion cells layer; IPL, inner plexiform layer; INL, inner nuclear layer; OPL, outer plexiform layer; ONL, outer nuclear layer; Ctr, sham-operated control; G1 day, 1 day following surgery; G3 days, 3 days following surgery; G1-4 weeks, 1-4 weeks following surgery; $\mathrm{Ca}_{\mathrm{v}}$, calcium channel; $\mathrm{COH}$, chronic ocular hypertension.

level didn't change much in the initial period of time (G1 day and G3 days) and started increasing in G1 week (164.7 $\pm 3.4 \%$ of control, $\mathrm{n}=4, \mathrm{P}=0.002$ ) and remained at stable higher level thereafter, which were $175.7 \pm 3.2 \%$ of control at $\mathrm{G} 2$ weeks $(n=4$, $\mathrm{P}=0.001), 228.5 \pm 15.6 \%$ of control at $\mathrm{G} 3$ weeks $(\mathrm{n}=4, \mathrm{P}<0.001)$, and $210.6 \pm 15.9 \%$ of control at $\mathrm{G} 4$ weeks $(\mathrm{n}=4, \mathrm{P}<0.001)$. In contrast, the average intensity of $\mathrm{Ca}_{\mathrm{v}} 3.3$ subunit of T-type $\mathrm{Ca}^{2+}$ channels and $\mathrm{Ca}_{\mathrm{v}} 1.2$ subunit of L-type $\mathrm{Ca}^{2+}$ channels didn't change during the whole postoperational period.

Immunofluorescence analysis further demonstrated that $\mathrm{Ca}_{\mathrm{v}} 3.1$ and $\mathrm{Ca}_{\mathrm{v}} 3.2$ subunit of T-type $\mathrm{Ca}^{2+}$ channels were expressed in different locations. $\mathrm{Ca}_{\mathrm{v}} 3.1$ was mainly expressed in the outer plexiform layer (OPL) and cell membranes in inter nuclear layer (INL) (Fig. 2); during G1 day and G3 days, most of the $\mathrm{Ca}_{\mathrm{v}} 3.1$ signal was located in the OPL (Fig. 2Ab and c), while later the signal was also found in the INL (from G1 week to G3 weeks, Fig. 2Ad-f). $\mathrm{Ca}_{\mathrm{v}} 3.2$ was mainly located in GCL layer; the signal increased from G1 week through G4 weeks (Fig. 3Ad-g and Cd-g). Furthermore, all those data were consistent with western blot results. Moreover, since GCL layer was most vulnerable to IOP, we then verified whether RGCs and Müller cells were both positive for $\mathrm{Ca}_{\mathrm{v}} 3.2$ expressions (Fig. 4A and E), by co-localization with CTB (Fig. 4B) and GFAP (Fig. 4D), respectively.

Mibefradil reduced RGCs apoptosis in EphB2-Fc injected rat retina. In our previous study, we have shown that intravitreal injection of EphB2-Fc induces apoptosis in RGCs. Since $\mathrm{Ca}_{\mathrm{v}} 3.2$ was increased in the RGCs and Müller cells in $\mathrm{COH}$ rats, in the present study we used $\mathrm{T}$ type $\mathrm{Ca}^{2+}$ channel blocker Mibefradil to further investigate whether calcium channels were involved in the process of EphB2-Fc induced apoptosis in RGCs. As Fig. 5 showed, average TUNEL signals that matched well with DAPI in GCL by EphB2-Fc injection were 497.4 \pm 25.3 , significantly higher than control Fc treatment $(17.2 \pm 2.9, \mathrm{n}=5, \mathrm{P}<0.001)$. Pretreatment of Mibefradil $(2 \mu 1$, $3 \mathrm{mM}$ ), injected intravitreally 1 day before EphB2-Fc, reduced the TUNEL signals to $302.4 \pm 16.3$ ( $n=5, P<0.001$, compared with EphB2-Fc group) while saline pretreatment had no effect (505.2 $\pm 26.1, n=5, P=0.64$, compared with EphB2-Fc group).

\section{Discussion}

We have previously reported that elevated reverse EphB/ephrinB signaling contributes to RGCs apoptosis by interacting with GluR2 subunit of AMPA receptors in a $\mathrm{COH}$ rat model (16). By using the same ocular hypertension rat model, we found that $\mathrm{Ca}_{\mathrm{v}} 3.1$ and $\mathrm{Ca}_{\mathrm{v}} 3.2$ protein expression increased in retinas, but at different locations and at different timepoints. It is necessary to emphasize that $\mathrm{Ca}_{\mathrm{v}} 3.2$ increased both in RGCs and Müller cells in $\mathrm{COH}$ retinas, which was similar to the expression pattern of ephrinB2, with the exception that ephrinB2 starts to increase from second week (16) while increment of $\mathrm{Ca}_{\mathrm{v}} 3.2$ started in $\mathrm{G} 1$ week. Consequently, RGCs apoptosis caused by intravitreal injection of clustered EphB2-Fc could be partly relieved by Mibefradil, a $\mathrm{T}$ type $\mathrm{Ca}^{2+}$ channel blocker. Numerous studies have shown that disturbance of calcium homeostasis which occurs through several pathways contributes to neuronal damage in many neurodegenerative diseases (27-32). Moreover, the deregulation of $\mathrm{Ca}^{2+}$ channel activities, which is one of the pathways causing $\mathrm{Ca}^{2+}$ homeostasis disturbance, has very important 


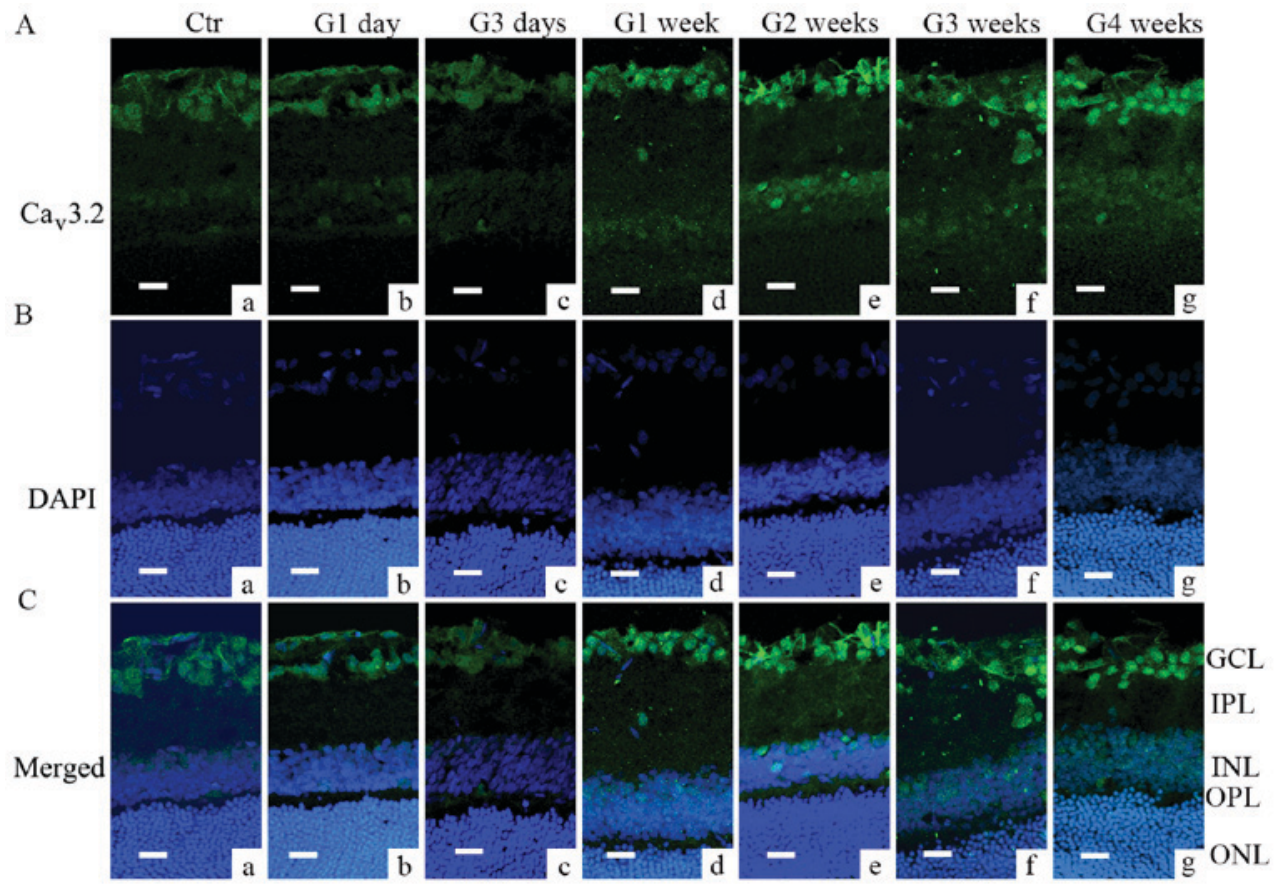

Figure 3. $\mathrm{Ca}_{v} 3.2$ expression in $\mathrm{COH}$ rats examined by immunofluorescence. (A) $\mathrm{Ca}_{v} 3.2$ expression profiles in rat retinal vertical slices taken from sham-operated retinas (Ctr; image a), and those obtained from $\mathrm{COH}$ rats at different time points (images b-g). (B) DAPI signal in retinas of control (image a), and those obtained from $\mathrm{COH}$ rats at different time points (images b-g). (C) Merged images of $\mathrm{Ca}_{\mathrm{v}} 3.2$ and DAPI in retinas of control (image a), and those obtained from $\mathrm{COH}$ rats at different time points (images b-g). Scale bars=20 $\mu \mathrm{m}$. GCL, ganglion cells layer; IPL, inner plexiform layer; INL, inner nuclear layer; OPL, outer plexiform layer; ONL, outer nuclear layer; Ctr, sham-operated control; G1 day, 1 day following surgery; G3 days, 3 days following surgery; G1-4 weeks, 1-4 weeks following surgery; $\mathrm{Ca}_{\mathrm{v}}$, calcium channel; $\mathrm{COH}$, chronic ocular hypertension.
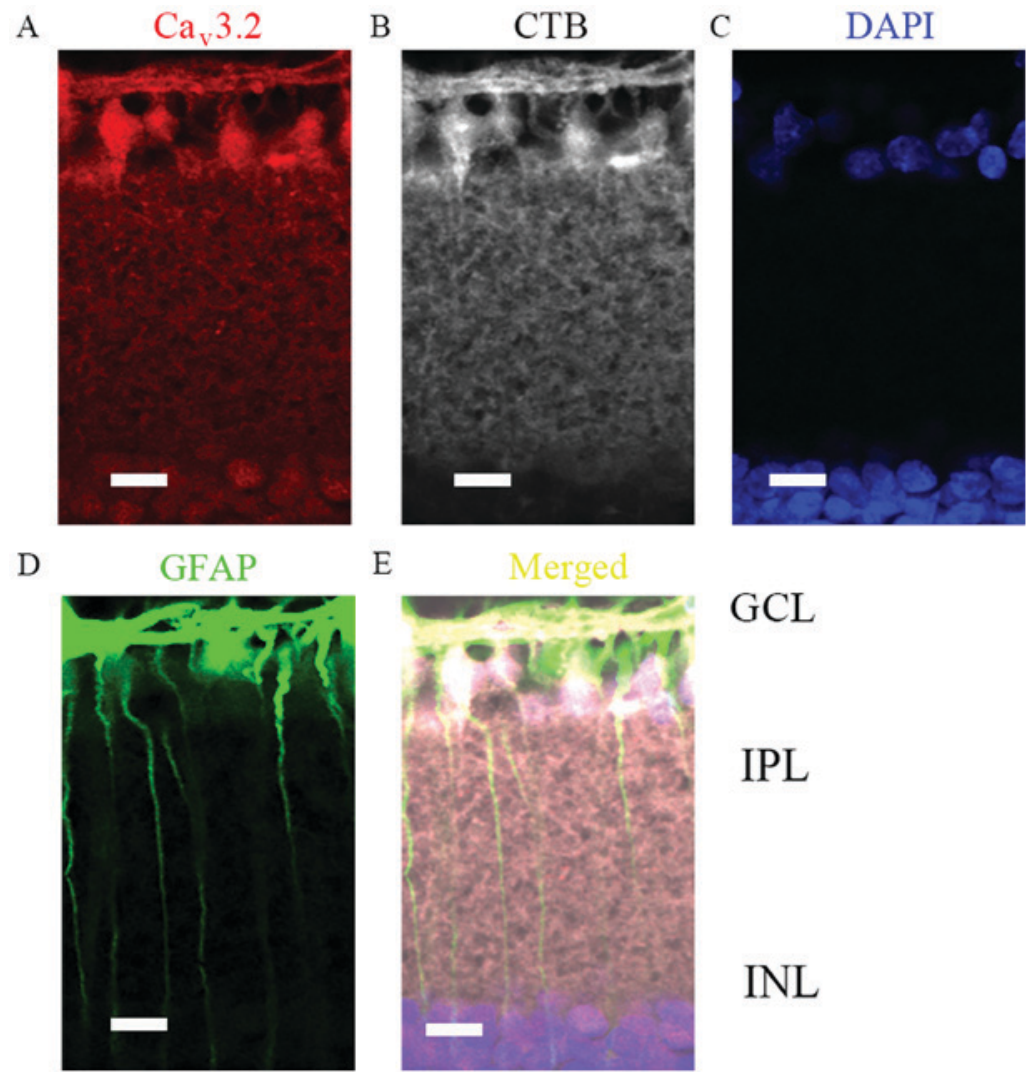

\section{GCL}

IPL

\section{INL}

Figure 4. $\mathrm{Ca}_{\mathrm{v}} 3.2$ expression location in $\mathrm{COH}$ retinas (G2 weeks) by immunofluorescence analysis. (A) Immunofluorescence labeling for Ca 3.2 in $\mathrm{G} 2$ week rat retinal vertical slices following an injection of CTB to the superior colliculus bilaterally. (B) Immunofluorescence labeling for CTB (positive for retinal ganglion cells) in the retinal vertical slices. (C) Immunofluorescence labeling for DAPI in the retinal vertical slices. (D) Immunofluorescence labeling for GFAP (positive for Müller cells) in the retinal vertical slices. (E) Merged images of Ca 3.2 , CTB, DAPI and GFAP in the retinal vertical slices. Scale bars $=20 \mu \mathrm{m}$. Ca , calcium channel; $\mathrm{COH}$, chronic ocular hypertension; G2 weeks, 2 weeks following surgery; GCL, ganglion cells layer; IPL, inner plexiform layer; INL, inner nuclear layer; CTB, Cholera Toxin B subunit; GFAP, glial fibrillary acidic protein. 
A
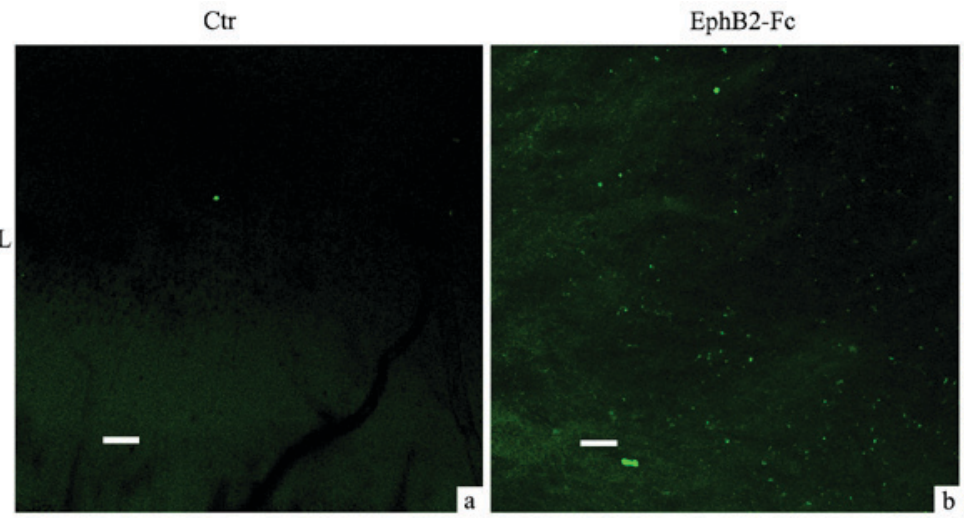

B
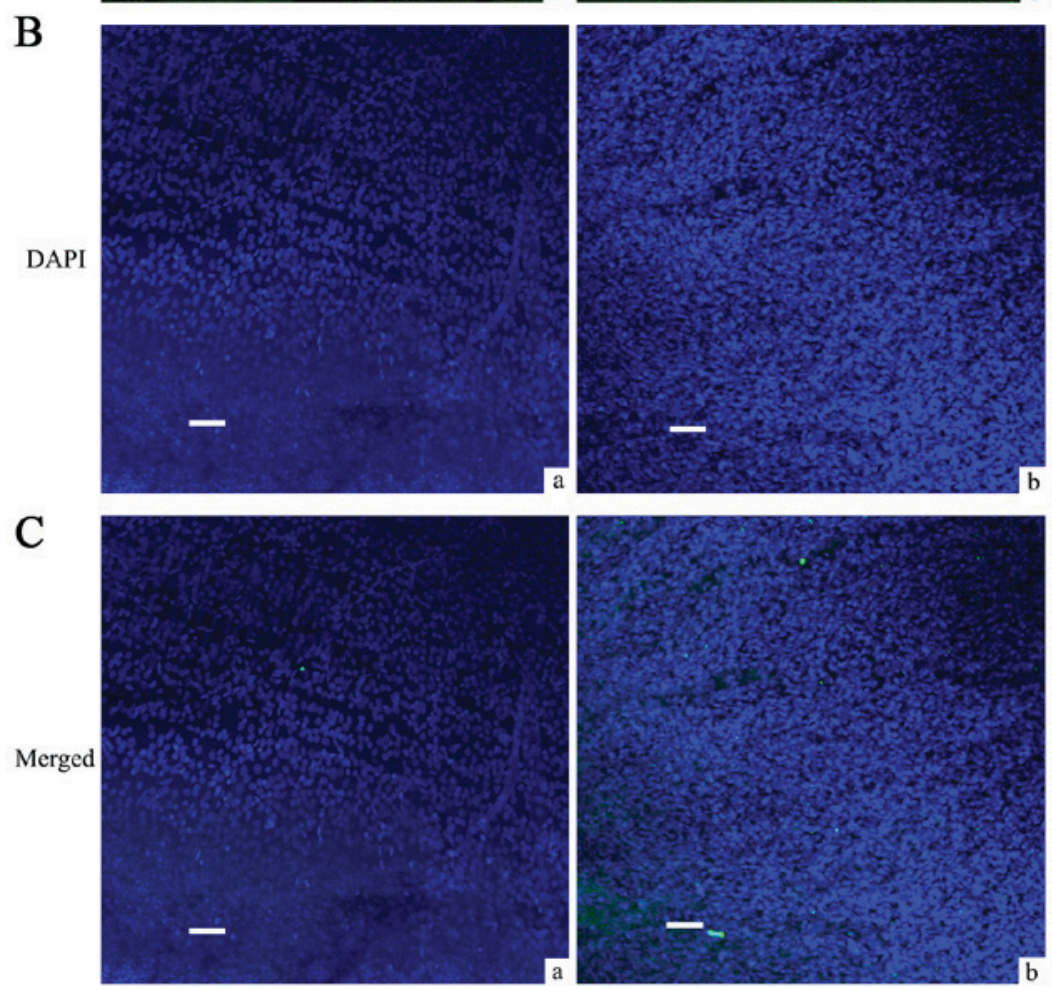

Mibefradil+EphB2-Fc
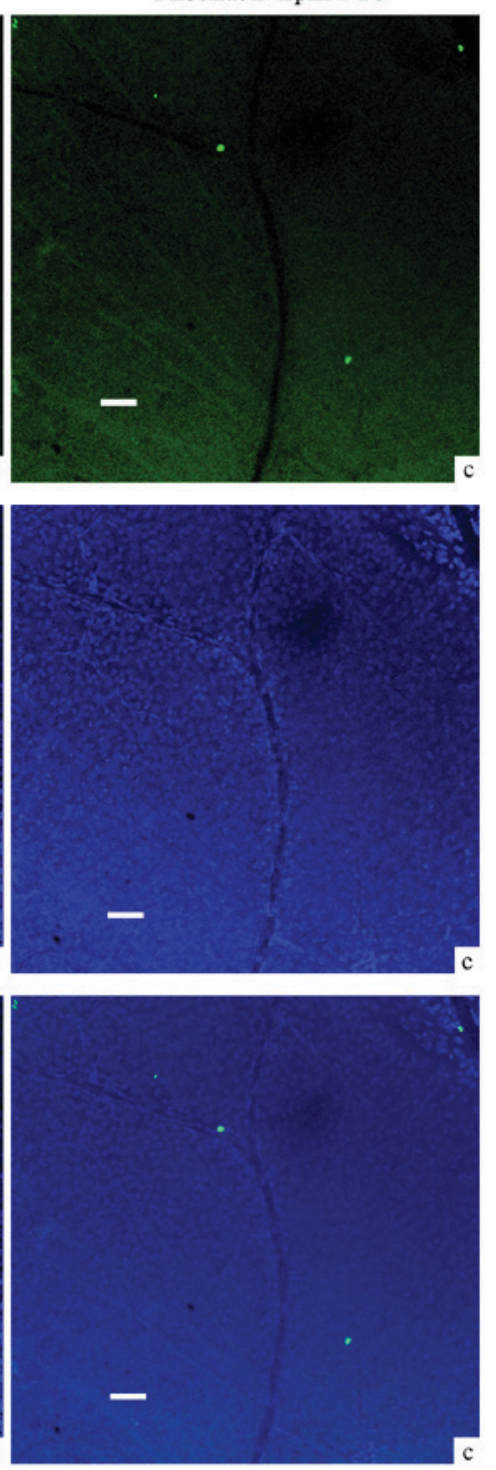

Figure 5. Pretreatment with Mibefradil reduced EphB2-Fc induced apoptosis in retinal ganglion cells. (A) TUNEL signaling, (B) DAPI staining and (C) merged images in the retinas of the control, EphB2-Fc and Mebefradil with EphB2-Fc groups. Scale bars=50 $\mu \mathrm{m}$. Ctr, sham-operated control; EphB2-Fc, erythropoietin-producing hepatocyte receptor B2-fragment crystallizable region.

role in neurodegenerative disease like ALS (33) although related reports are relatively rare and controversial (34). In glaucoma, like in many other neurodegenerative diseases, $\mathrm{Ca}^{2+}$ channel blockers have shown to be beneficial (reviewed by Chihiro Mayama in reference) (35). The most often tested $\mathrm{Ca}^{2+}$ channel blockers in experimental models are $\mathrm{L}$ type $\mathrm{Ca}^{2+}$ channel blockers, nifedipine and nimodipine. Their benefits include lowered IOP, improved blood flow to RGCs and neuron protection due to less $\mathrm{Ca}^{2+}$ influx. In the present study, we didn't test $\mathrm{L}$ type $\mathrm{Ca}^{2+}$ channel blockers' effect on the EphB2-Fc induced RGCs apoptosis, since no changes in $\mathrm{L}$ type $\mathrm{Ca}^{2+}$ channel expression were observed in $\mathrm{COH}$ retinas. Nonetheless, we didn't totally rule out the possibility that $\mathrm{L}$ type $\mathrm{Ca}^{2+}$ channel could play a role, for in our other separated preliminary experiments (data not shown here), clustered EphB2-Fc increased mixed $\mathrm{Ca}^{2+}$ currents in isolated Müller cells. If this was the same as with RGCs or whether it was related with Mibefradil's protection on
RGCs needs to be further examined. Our results suggest that elevated EphB/ephrinB signaling regulates RGCs apoptosis under $\mathrm{COH}$ through more than one pathway, while calcium channels, i.e., T type calcium channel, might be a target for EphB/ephrinB signaling. Another important point that needs to be addressed is the way EphB/ephrinB signaling regulates calcium channels in rat retinas. It is well known that phosphorylation of calcium channels is important for the function. Previous studies have shown that L type calcium channel could be regulated by tyrosine kinase src (36-38). According to our previous findings, EphB/ephrinB signaling in retina could interact with src (16). Src kinase acts as a downstream of $\mathrm{Ca} 2+/$ calmodulin-dependent protein kinase II (CaMK II) in intracellular free $[\mathrm{Ca} 2+]_{\mathrm{i}}$ glomerular mesangial cells (39), while in striatum basal level of autophosphorylation of CaMK II it requires T type, but not L or N type calcium channels (40). Although, using high resolution MS approach several threonine and serine residues with no tyrosine phosphorylation 
have been detected in normal rat brain tissue (41), the situation in retina, especially under higher IOP remains an open question.

\section{Acknowledgements}

This study was supported by the Natural Science Foundation of Hubei Province (no. 2014CFB213), the Health and Birth Control Department of Hubei Province (no. 81000380/H1204) and the Jingzhou Science and Technology funding (2014AC47B). We thank the grants that supported our study and MedSci (www.MedSci.com) for its linguistic assistance during the preparation of this manuscript.

\section{References}

1. Pasquale EB: Eph receptor signaling casts a wide net on cell behavior. Nat Rev Mol Cell Biol 6: 462-475, 2005

2. Yamaguchi $Y$ and Pasquale EB: Eph receptors in the adult brain. Curr Opin Neurobiol 14: 288-296, 2004.

3. Pasquale EB: Eph-ephrin bidirectional signaling in physiology and disease. Cell 133: 38-52, 2008.

4. Egea $\mathbf{J}$ and Klein R: Bidirectional Eph-ephrin signaling during axon guidance. Trends Cell Biol 17: 230-238, 2007.

5. Himanen JP, Saha N and Nikolov DB: Cell-cell signaling via Eph receptors and ephrins. Curr Opin Cell Biol 19: 534-542, 2007.

6. Klein R: Bidirectional modulation of synaptic functions by Eph/ephrin signaling. Nat Neurosci 12: 15-20, 2009.

7. Chen Y,Fu AK and Ip NY: Eph receptors at synapses: Implications in neurodegenerative diseases. Cell Signal 24: 606-611, 2012.

8. Lai KO and Ip NY: Synapse development and plasticity: Roles of ephrin/Eph receptor signaling. Curr Opin Neurobiol 19: 275-283, 2009.

9. Dalva MB, Takasu MA, Lin MZ, Shamah SM, Hu L, Gale NW and Greenberg ME: EphB receptors interact with NMDA receptors and regulate excitatory synapse formation. Cell 103 945-956, 2000

10. Takasu MA, Dalva MB, Zigmond RE and Greenberg ME: Modulation of NMDA receptor-dependent calcium influx and gene expression through EphB receptors. Science 295: 491-495, 2002.

11. Grunwald IC, Korte M, Adelmann G, Plueck A, Kullander K, Adams RH,Frotscher M,BonhoefferT and Klein R: Hippocampal plasticity requires postsynaptic ephrinBs. Nat Neurosci 7: 33-40, 2004.

12. Calò L, Spillantini M, Nicoletti F and Allen ND: Nurrl co-localizes with EphB1 receptors in the developing ventral midbrain, and its expression is enhanced by the EphB1 ligand, ephrinB2. J Neurochem 92: 235-245, 2005.

13. Calò L, Cinque C, Patanè M, Schillaci D, Battaglia G, Melchiorri D, Nicoletti $F$ and Bruno V: Interaction between ephrins/Eph receptors and excitatory amino acid receptors: Possible relevance in the regulation of synaptic plasticity and in the pathophysiology of neuronal degeneration. J Neurochem 98 : $1-10,2006$

14. Du J, Tran T, Fu C and Sretavan DW: Upregulation of EphB2 and ephrin-B2 at the optic nerve head of DBA/2J glaucomatous mice coincides with axon loss. Invest Ophthalmol Vis Sci 48 : 5567-5581, 2007.

15. Fu CT, Tran T and Sretavan D: Axonal/glial upregulation of EphB/ephrin-B signaling in mouse experimental ocular hypertension. Invest Ophthalmol Vis Sci 51: 991-1001, 2010.

16. Dong LD, Gao F, Wang XH, Miao Y, Wang SY, Wu Y, Li F, Wu J, Cheng XL, Sun XH, et al: GluA2 trafficking is involved in apoptosis of retinal ganglion cells induced by activation of $\mathrm{EphB} /$ EphrinB reverse signaling in a rat chronic ocular hypertension model. J Neurosci 35: 5409-5421, 2015.

17. Sappington RM, Sidorova T, Long DJ and Calkins DJ: TRPV1: Contribution to retinal ganglion cell apoptosis and increased intracellular $\mathrm{Ca} 2+$ with exposure to hydrostatic pressure. Invest Ophthalmol Vis Sci 50: 717-728, 2009.

18. Ryskamp DA, Witkovsky P, Barabas P, Huang W, Koehler C, Akimov NP, Lee SH, Chauhan S, Xing W, Rentería RC, et al: The polymodal ion channel transient receptor potential vanilloid 4 modulates calcium flux, spiking rate, and apoptosis of mouse retinal ganglion cells. J Neurosci 31: 7089-7101, 2011.
19. Poornima V, Madhupriya M, Kootar S, Sujatha G, Kumar A and Bera AK: P2X7 receptor-pannexin 1 hemichannel association: Effect of extracellular calcium on membrane permeabilization. J Mol Neurosci 46: 585-594, 2012.

20. Bissig D, Goebel D and Berkowitz BA: Diminished vision in healthy aging is associated with increased retinal L-type voltage gated calcium channel ion influx. PLoS One 8: e56340, 2013.

21. Tomita G: The optic nerve head in normal-tension glaucoma. Curr Opin Ophthalmol 11: 116-120, 2000.

22. Wang SY, Singh K and Lin SC: The association between glaucoma prevalence and supplementation with the oxidants calcium and iron. Invest Ophthalmol Vis Sci 53: 725-731, 2012.

23. Chen J, Miao Y, Wang XH and Wang Z: Elevation of $\mathrm{p}-\mathrm{NR} 2 \mathrm{~A}(\mathrm{~S} 1232)$ by $\mathrm{Cdk} 5 / \mathrm{p} 35$ contributes to retinal ganglion cell apoptosis in a rat experimental glaucoma model. Neurobiol Dis 43: 455-464, 2011

24. Ji M, Miao Y, Dong LD, Chen J, Mo XF, Jiang SX, Sun XH, Yang XL and Wang Z: Group I mGluR-mediated inhibition of Kir channels contributes to retinal Müller cell gliosis in a rat chronic ocular hypertension model. J Neurosci 32: 12744-12755, 2012.

25. Yang W, Li Q, Wang SY, Gao F, Qian WJ, Li F, Ji M, Sun XH, Miao Y and Wang Z: Cannabinoid receptor agonists modulate calcium channels in rat retinal Müller cells. Neuroscience 313: 213-224, 2016.

26. Calò L, Bruno V, Spinsanti P, Molinari G, Korkhov V, Esposito Z, Patanè M, Melchiorri D, Freissmuth $\mathrm{M}$ and Nicoletti F: Interactions between ephrin-B and metabotropic glutamate 1 receptors in brain tissue and cultured neurons. J Neurosci 25: 2245-2254, 2005.

27. Hallett PJ and Standaert DG: Rationale for and use of NMDA receptor antagonists in Parkinson's disease. Pharmacol Ther 102: 155-174, 2004.

28. Surmeier DJ: Calcium ageing, and neuronal vulnerability in Parkinson's disease. Lancet Neurol 6: 933-938, 2007.

29. Fan MM and Raymond LA: N-methyl-D-aspartate (NMDA) receptor function and excitotoxicity in Huntington's disease. Prog Neurobiol 81: 272-293, 2007.

30. Bezprozvanny I: Inositol 1,4,5-tripshosphate receptor, calcium signalling and Huntington's disease. Subcell Biochem 45: 323-335, 2007.

31. Bezprozvanny I and Mattson MP: Neuronal calcium mishandling and the pathogenesis of Alzheimer's disease. Trends Neurosci 31: 454-463, 2008.

32. Green KN and LaFerla FM: Linking calcium to Abeta and Alzheimer's disease. Neuron 59: 190-194, 2008.

33. Delbono O, Garcia J, Appel SH and Stefani E: IgG from amyotrophic lateral sclerosis affects tubular calcium channels of skeletal muscle. Am J Physiol 260: C1347-C1351, 1991.

34. Arsac C, Raymond C, Martin-Moutot N, Dargent B, Couraud F, Pouget $\mathbf{J}$ and Seagar M: Immunoassays fail to detect antibodies against neuronal calcium channels in amyotrophic lateral sclerosis serum. Ann Neurol 40: 695-700, 1996

35. Mayama C: Calcium channels and their blockers in intraocular pressure and glaucoma. Eur J Pharmacol 739: 96-105, 2014.

36. Hu XQ, Singh N, Mukhopadhyay D and Akbarali HI: Modulation of voltage-dependent $\mathrm{Ca} 2+$ channels in rabbit colonic smooth muscle cells by c-Src and focal adhesion kinase. J Biol Chem 273: 5337-5342, 1998.

37. Bence-Hanulec KK, Marshall J and Blair LA: Potentiation of neuronal $\mathrm{L}$ calcium channels by IGF-1 requires phosphorylation of the alpha1 subunit on a specific tyrosine residue. Neuron 27: 121-131, 2000.

38. Bogdelis A, Treinys R, Stankevičius E, Jurevičius J and Skeberdis VA: Src family protein tyrosine kinases modulate L-type calcium current in human atrial myocytes. Biochem Biophys Res Commun 413: 116-121, 2011.

39. Wang Y, Mishra R and Simonson MS: Ca2+/calmodulin-dependent protein kinase II stimulates c-fos transcription and DNA synthesis by a Src-based mechanism in glomerular mesangial cells. J Am Soc Nephrol 14: 28-36, 2003.

40. Pasek JG, Wang X and Colbran RJ: Differential CaMKII regulation by voltage-gated calcium channels in the striatum. Mol Cell Neurosci 68: 234-243, 2015.

41. Blesneac I, Chemin J, Bidaud I, Huc-Brandt S, Vandermoere F and Lory P: Phosphorylation of the Cav3.2 T-type calcium channel directly regulates its gating properties. Proc Natl Acad Sci USA 112: 13705-13710, 2015.

This work is licensed under a Creative Commons Attribution-NonCommercial-NoDerivatives 4.0 International (CC BY-NC-ND 4.0) License. 